\title{
O uso de Relações Pedagógicas em aulas de Patologia Geral: materialização do elo com o currículo e a profissão
}

\author{
The use of Pedagogical link-making in General Pathology \\ classes: materialization of the link with the curriculum \\ and with the profession
}

\author{
Reane Fonseca Martins ${ }^{1}$. http://orcid.org/0000-0002-8256-9799 \\ Luciana Moro $^{1}$. https://orcid.org/0000-0003-1006-3964 \\ Eduardo Fleury Mortimer ${ }^{2}$. https://orcid.org/0000-0002-3025-121X
}

\begin{abstract}
Resumo: O objetivo desse artigo é identificar e quantificar se os professores materializam o elo que a Patologia Geral representa entre as disciplinas básicas e as profissionalizantes, e se eles reconhecem esse feito. Usamos um referencial teórico-metodológico que analisa relações pedagógicas (RP) para avaliar aulas de cinco professores de Patologia Geral de uma universidade pública federal. Para tanto, escolhemos aulas gravadas em vídeo, cuja sequência didática foi a de neoplasia. Adicionalmente, fizemos entrevistas semiestruturadas com os cinco professores. Observamos que os professores efetuam as RPs idiossincraticamente. As RPs macro e os exemplos contextualizados na profissão, que evidenciam a materialização do elo, ocorrem em menor número que as demais relações pedagógicas. Concluímos que, como as RPs que efetivam o elo ocorrem em menor frequência, justifica-se, em parte, o desinteresse de alguns estudantes nas aulas de Patologia Geral.
\end{abstract}

Palavras-chave: Ensino de patologia. Ensino superior. Relações pedagógicas.

\begin{abstract}
The objective of this article is to verify and quantify if the professors materialize the link that General Pathology represents between the basic and professional disciplines and if they recognize this achievement. We are based in a theoretical framework analyzing pedagogical link-making (PLM) developed in classes of five professors of General Pathology from a Brazilian Federal University. To do this, we chose classes recorded in video, whose didactic sequence was based on neoplasia. We also did a semi-structured interview with five professors. We observed that the professors do PLM idiosyncratically. The Meso and Micro PLM were more emphasized by the professors and as the macro professionals were under represented, we conclude this may partially influence the academics' lack of interest in the discipline.
\end{abstract}

Keywords: Pathology teaching. Pedagogical link-making. Higher education.

\footnotetext{
${ }^{1}$ Universidade Federal de Minas Gerais (UFMG), Instituto de Ciências Biológicas, Departamento de Patologia, Belo Horizonte, MG, Brasil. E-mail: <reanefm@yahoo.com.br>.

${ }^{2}$ UFMG, Faculdade de Educação, Belo Horizonte, MG, Brasil.
} 


\section{Introdução}

A Patologia Geral é uma ciência que estuda a doença no seu aspecto funcional e morfológico. Segundo a Lei de Diretrizes e Bases de 1996 (BRASIL, 1996), essa disciplina é obrigatória a todos os cursos superiores da área de saúde, tais como: Medicina, Enfermagem, Medicina Veterinária, Nutrição, Ciências Biomédicas, Fisioterapia, Terapia Ocupacional, Farmácia, Fonoaudiologia e Odontologia. (MELO-JÚNIOR et al., 2007).

A Patologia Geral é ministrada, geralmente, entre o terceiro e quarto períodos desses cursos e, para que seus conceitos sejam construídos, é necessário que o estudante tenha uma bagagem de conhecimentos de várias disciplinas básicas (Biologia Celular, Histologia, Anatomia, Fisiologia, Embriologia, Bioquímica, entre outras). Além disso, os conceitos nela construídos embasam a construção de conhecimento nas disciplinas profissionalizantes (Patologias Especiais, Patologia Clínica e Cirúrgica, Clínicas Diversas, Inspeção de Carne) e também nos estágios curriculares obrigatórios presentes em vários desses cursos. Por isso mesmo, ela é considerada por muitos estudiosos da área, como um elo entre as disciplinas básicas e as profissionalizantes (BRASILEIRO FILHO, 2013; FENDERSON, 2005; KUMAR et al., 2010; MARSHALL; CARTWRIGHT; MATTTICK, 2004; MELO-JÚNIOR et al., 2007; NEVES et al., 2008; TAVARES, 2008, etc).

Há ainda autores que têm uma visão "patocêntrica" do currículo médico (REISNER, 2016), por considerarem a Patologia como o cerne do curso de Medicina. Nesse sentido, para o estudante, segundo Vasconcelos (2000), a Patologia Geral deve ser encarada como uma matéria interessante, pois representa o primeiro contato com a terminologia médica. Ela também é considerada importante, pois é a compreensão do mecanismo de formação das doenças que vai ser a base para a boa prática clínica, potenciando diagnósticos e indicando terapêuticas. Esse autor ainda afirma que, para o bom clínico, a patologia representa um suporte para a confirmação de diagnósticos. Nesse sentido, o processo patológico constitui elemento primário da intervenção da área da saúde, esteja ela voltada para a prevenção, tratamento, reabilitação ou diagnóstico das doenças (TAVARES, 2008).

Com base nisso, acreditamos que, para que o estudante de Patologia Geral tome consciência da sua importância no currículo e na sua vida profissional, esses aspectos devem ser explicitados durante as aulas por meio de estratégias pedagógicas.

Porém, o que nos parece, por meio de nossa prática docente, é que muitos estudantes mostram-se desinteressados e desmotivados nas aulas. Também observamos, na fala de alguns professores que entrevistamos, queixas semelhantes sobre o comportamento dos alunos durante suas aulas. Além disso, fizemos uma pesquisa paralela, aplicando questionários para 321 estudantes de Patologia Geral, por meio da qual verificamos que 17\% dos estudantes, principalmente dos cursos de Fisioterapia (33\%) e Terapia Ocupacional (60\%), sugeriram que a disciplina deveria apresentar maior relação com a profissão. Desse modo surgiram as perguntas: Os professores costumam relacionar os conteúdos da disciplina com a profissão em suas aulas? Que tipo de relações pedagógicas eles estabelecem?

Uma hipótese é que a importância da disciplina no currículo e na futura profissão do estudante não esteja sendo explicitada em sala de aula. Sendo assim, definimos os seguintes objetivos para este artigo: (1) identificar se os professores estudados efetivam o elo que a $\mathrm{Pa}$ tologia Geral representa entre as disciplinas básicas e as profissionalizantes, por meio das RPs efetuadas para estudantes de diferentes cursos; (2) identificar se os professores evidenciam a importância da disciplina para a futura profissão. 
Para isso, apoiamo-nos no referencial teórico-metodológico de Relações Pedagógicas elaborado por Scott, Mortimer, Amettler (2011), que se refere às formas pelas quais os professores e seus estudantes fazem ligações entre ideias veiculadas no discurso da sala de aula, para a construção de significados.

\section{As Relações Pedagógicas (RP)}

Um dos princípios básicos da perspectiva de aprendizagem construtivista é que, para adquirir conhecimento conceitual, o estudante deve estabelecer relações entre os conhecimentos existentes e as novas ideias. Baseado nisso, Scott, Mortimer, Amettler (2011) desenvolveram a concepção de Relações Pedagógicas (RP). Por meio dessas relações, os autores analisam como ocorre a construção de significados a partir de ideias veiculadas no discurso da sala de aula entre os professores e seus estudantes.

Nesse cenário, tanto os docentes como os alunos, ocupam papéis centrais: o professor deve criar ligações no plano social da sala de aula, a fim de apoiar os discentes na construção de relações no plano pessoal; os alunos, por sua vez, devem se responsabilizar por seu próprio aprendizado, realizando essas relações no plano psicológico. Se essas relações não forem construídas por meio do ensino, é provável que a aprendizagem não ocorra (SCOTT'; MORTIMER; AMETLLER, 2011).

Em seu trabalho, os autores supracitados, identificaram três formas de criar vínculos pedagógicos: (a) as RPs que dão suporte à construção de conhecimento; (b) as RPs que promovem a continuidade e (c) as RPs que encorajam o envolvimento emocional dos estudantes.

Nesse artigo, analisaremos somente as RPs que apoiam a construção de conhecimento e as que promovem a continuidade, pois elas nos permitem identificar, se nas aulas estudadas, ocorre a conexão da disciplina com o currículo e/ ou com a futura profissão dos estudantes. Segundo Santos (1996), para se trabalhar com pesquisa envolvendo a afetividade no campo da Educação em Ciências, o pesquisador deve abordar as diferenças individuais, as motivações e as crenças e relacioná-las a fatores cognitivos de cada sujeito do processo de ensino-aprendizagem. Esses objetivos ultrapassam os limites deste artigo, e por isso as RPs que encorajam o envolvimento emocional dos estudantes não serão abordadas.

\section{Relações pedagógicas que apoiam a construção de conhecimento}

Para Scott, Mortimer, Amettler (2011), o apoio à construção do conhecimento envolve seis tipos de abordagem que relacionam os diferentes tipos de conhecimento (Figura 1) e podem ocorrer individualmente ou se sobrepor.

Neste artigo, entre essas RPs que apoiam a construção do conhecimento, vamos nos limitar à análise daquelas que ligam conceitos científicos e fenômenos da vida real, pois, em nossa compreensão, elas materializam o elo que a Patologia Geral representa entre a disciplina e a profissão. Essas RPs são reconhecidas na fala dos professores, no momento em que eles explicam os processos patológicos ${ }^{3}$, por meio de exemplos profissionais. Nesse sentido, os fenômenos

\footnotetext{
${ }^{3}$ Para efeito deste artigo, trataremos como conceitos da patologia os mecanismos e processos patológicos.
} 
da vida real a que nos referimos neste artigo tratam-se de exemplos de processos patológicos que surgem na vida de profissionais da área da saúde. Ainda que os professores investigados realizem outros tipos de RPs que apoiam a construção do conhecimento, essas relações não fornecem indícios de que a disciplina seja importante para a vida profissional do estudante. Por exemplo, ao fazer a analogia da morfologia de um tumor com uma couve flor, ou ao retomar os conceitos de tumor aprendidos na inflamação para diferenciá-lo de outro tumor, estudado na neoplasia, o professor faz relações que apoiam a construção de conhecimento, mas não efetiva o elo da disciplina com o currículo e com a profissão.

Figura 1. As relações pedagógicas que apoiam a construção de conhecimento e suas seis abordagens

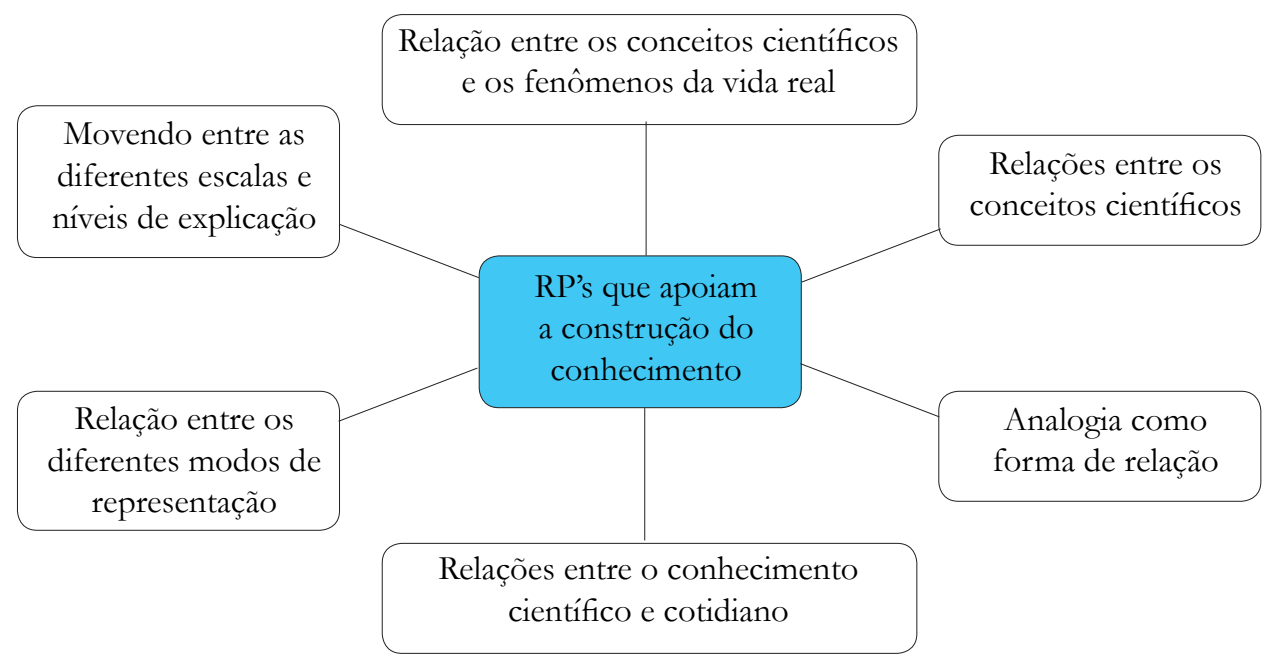

Fonte: Adaptado de Scott, Mortimer e Amettler (2011).

\section{Relação entre as explicações científicas e os fenômenos da vida real}

Em um contexto de ensino e aprendizagem, existe o risco de o estudante não estabelecer ligações entre os conceitos científicos e os fenômenos da vida real. Assim, esses conceitos não apresentam fundamento prático. Entretanto, para se evitar a formação de conceitos "vazios", o professor tem o desafio de adensar as ideias científicas com o concreto, para que os estudantes possam fazer as conexões. Entre as estratégias adotadas por professores para estabelecer essas relações, incluem-se: (i) trazer fatos relevantes e de interesse para os estudantes; (ii) resgatar um "evento memorável", ou seja, o professor relembra um fato que ocorreu em sala e que houve a participação da turma. Ao fazer isso, o professor contribui também com as RPs de Continuidade e com o Engajamento Emocional; (iii) avaliar as demandas de aprendizagem dos estudantes e escolher os fenômenos de acordo com elas. 
Considerando que Scott, Mortimer e Amettler (2011) desenvolveram essas RPs para aulas do ensino fundamental, fizemos adaptações para que fossem contempladas as características do ensino superior e dos cursos envolvidos.

No ensino superior, essa vida real não é, necessariamente, o dia a dia do estudante. Ela só será vivenciada quando o estudante estiver no estágio ou já atuando na profissão. Assim é importante apresentar exemplos do dia a dia profissional para promover o aprendizado desses conceitos. Por isso, para a Patologia Geral, denominaremos essa RP de exemplos contextualizados na profissão. Ao considerarmos esta RP, é possível constatar que o professor tem conhecimento do currículo, além de demostrar a importância dessa disciplina para a vida profissional do estudante.

\section{Relações Pedagógicas de continuidade temporal}

Nessa abordagem, Scott, Mortimer e Amettler (2011) evidenciam que o processo de ensino e aprendizagem depende do estabelecimento de sequências temporais de ideias, conceitos, aplicações e procedimentos. O conjunto dessas sequências, forma aquilo que é denominado "estória científica” (LEACH; SCOTT, 2002). Para que os estudantes consigam fazer eficientemente as relações entre os conceitos aprendidos, é importante que o professor promova a continuidade entre essas ideias. Isso pode ser feito por meio da recuperação de pontos de vista ou conceitos levantados em aulas anteriores, na mesma aula, em aulas futuras e até em outras disciplinas. $\mathrm{O}$ desenvolvimento da "estória científica" e o gerenciamento/organização da sequência didática se desenrolam em três níveis de escala temporal:

a) Micro: RPs de continuidade produzidas em uma escala de tempo curto (minutos a horas), que referencia diferentes pontos dentro de uma mesma aula;

b) Meso: RPs de continuidade praticadas em uma escala de tempo intermediário (dias ou semanas), que envolvem fazer referências a diferentes conceitos, dentro de uma mesma ou diferentes sequência didática;

c) Macro: RPs desenvolvidas em uma escala de tempo prolongado (meses ou anos) e que remetem a diferentes disciplinas do currículo.

Entendemos que a formação profissional envolve o desenrolar da "estória científica" que forma o estudante e, simultaneamente, o introduz no campo profissional. Para que o estudante perceba o porquê das disciplinas presentes no currículo do seu curso, elas devem ser remetidas a outras disciplinas e às atividades relacionadas com aquela profissão. Além disso, devemos pensar em formar o profissional desde o seu primeiro contato com a universidade, ou seja, não é uma formação para o futuro, mas sim uma formação no presente, construindo esse profissional passo a passo. Além disso, em vários cursos da área de saúde os estudantes entram em contato direto com a profissão ao realizarem estágios curriculares. Dessa forma, consideramos importante o professor propiciar uma relação de continuidade entre a "estória científica" desenrolada em sala de aula e aquilo que o estudante vivencia nesses estágios e continuará a desenvolver, depois de graduado. Com base nisso, ajustamos a categoria Macro dividindo-a em dois tipos: (1) RPs de continuidade macro curriculares, que são aquelas que relacionam a Patologia Geral com outras disciplinas do currículo e que é, portanto, igual a RP macro; (2) RPs de continuidade macro profissionais, que ligam o conteúdo da disciplina com a prática dos profissionais nas suas respectivas áreas. O que diferencia as RPs macro profissionais dos exemplos contextualizados na profissão, que nós caracterizamos como um tipo de RP que 
apoia a construção de conhecimentos é que, nas RPs macro profissionais, é como se o professor transportasse os estudantes para a prática, comentando algo que é fundamentalmente uma característica da prática profissional. Isso não acontece no caso dos exemplos contextualizados, nos quais o professor simplesmente toma como exemplo um processo patológico básico característico do conhecimento profissional.

Notamos também que as relações macro poderiam aparecer de forma explícita ou implícita na fala dos professores. Por isso, nós as subdividimos de acordo. Assim, as RPs macro curriculares explícitas são aquelas nas quais o docente menciona claramente em qual disciplina os estudantes já viram um determinado tema ou em quais disciplinas eles irão utilizar os conceitos que estão sendo construídos em sala de aula. Já as RPs macro profissionais explícitas emergem quando o professor cita em qual área ou ação profissional aquele tema será necessário ou será utilizado. Já nas RPs macro curriculares e profissionais implícitas, o professor deixa de mencionar a disciplina ou a área profissional na qual aquele conceito foi ou será abordado.

Figura 2. Relações Pedagógicas de continuidades adaptadas de Scott, Mortimer e Ametller (2011) para o contexto de ensino superior

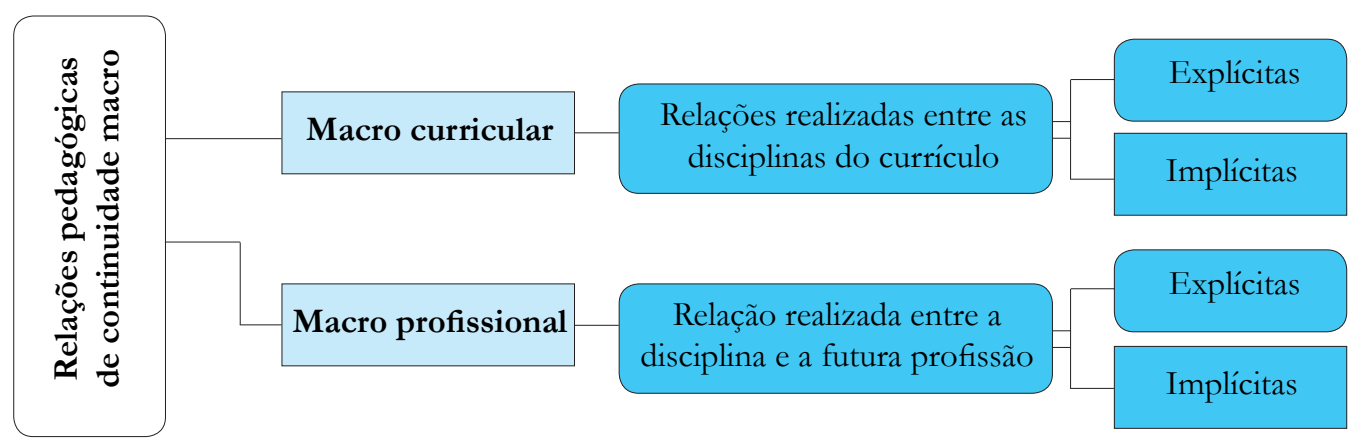

Fonte: elaborado pelos autores.

\section{Metodologia}

Filmamos um semestre de aulas de cinco professores do Departamento de Patologia Geral de uma Universidade Pública Federal, no período de 2014 a 2017. Dessas, escolhemos dezessete aulas teóricas, cuja sequência didática referia-se ao tema neoplasia.

Esses professores serão tratados aqui pelos nomes fictícios: Ana, Carlos, Elisa, Paulo e Tom e ministraram aula para as turmas de: Medicina, Farmácia, Odontologia, Biomedicina e Medicina Veterinária, respectivamente.

A análise das aulas baseou-se nas RPs propostas por Scott, Mortimer e Amettler (2011) considerando: (1) as relações entre explicações científicas e fenômenos da vida real; (2) as relações de continuidade micro, meso e macro, com as adaptações já discutidas. 
Uma entrevista semiestruturada foi empregada com objetivo de investigar em que medida a trajetória desses professores na Patologia Geral influencia a sua vida profissional.

Algumas falas foram transcritas e, para torná-las simples e facilitar a compreensão do leitor, adotamos um código simplificado para registrar alguns elementos de pontuação ligados à produção da linguagem oral (MORTIMER et al., 2007). Para indicar a mudança de tom ascendente, indicativo de uma pergunta, foi mantido o ponto de interrogação (?). O mesmo critério, agora com a mudança de tom descendente, foi usado para indicar ponto final. A barra, /, indica uma pausa de pouca duração. Quando as pausas duraram mais de 1 segundo, indicamos a duração entre parênteses. Caixa alta indica que a palavra foi pronunciada com ênfase (mais forte) e o sinal // indica uma fala que foi interrompida pela fala seguinte. Para indicar cortes ou supressões na fala utilizamos [...]. Utilizamos parênteses () para descrever o modo semiótico utilizado pelo professor, quando, somente a fala, não fazia sentido. Além disso, suprimimos as marcas de oralidade e regionalidade.

\section{Resultados}

Apresentaremos os resultados explicitando primeiramente as RPs encontradas nas aulas. Em seguida, apresentaremos a frequência de RPs quantificadas e finalizamos trazendo um breve perfil dos professores estudados.

\section{Exemplos das Relações Pedagógicas encontradas}

\section{Relações pedagógicas que apoiam a construção do conhecimento: RPs entre explicações científicas e fenômenos da vida real: Exemplos contextualizados na profissão.}

As relações pedagógicas que apoiam a construção do conhecimento, apresentando como abordagem a ligação entre os conceitos científicos e fenômenos da vida real, foram redefinidas como exemplos contextualizados na profissão.

Ana fez isso, ao explicar para os estudantes de Medicina o conceito de hipotrofia, quando empregou, como exemplo, a presença de cálculos renais, que são um dos causadores de hipotrofia renal. Nesse momento ela relatou: "Então / qual é o problema do cálculo? Não é somente porque dói. É porque ele acaba // vai causar uma hipotrofia do parênquima renal. Assim / a pessoa pode até chegar a perder o rim." Ou seja, ela trouxe um exemplo de alteração de ocorrência comum na Medicina (cálculos renais) e o relacionou com o conceito que ela estava ensinando (hipotrofia). Com isso, ela demonstrou a importância da disciplina no currículo médico e chamou a atenção dos estudantes para a aplicação de um conceito de um processo patológico básico.

\section{Relações pedagógicas de continuidade temporal}

a) Relações pedagógicas de continuidade do tipo micro

Por meio dessa relação, os docentes associam pontos tratados na mesma aula, contribuindo assim, para a coerência e coesão do discurso. Carlos fez essa relação, quando explicava 
o conceito de diferenciação e disse: "É importante que a gente entenda isso/ para entender as lesões que nós vamos estudar hoje”. Ao dizer essa frase, ele enfatizou a importância daquele conceito que estava sendo ensinado para o que seria apresentado a seguir.

b) Relações pedagógicas de continuidade do tipo meso

Sua efetivação demonstra que o professor retoma um conteúdo que já foi ou que será ensinado na mesma sequência didática, para auxiliar na construção de um novo conceito.

Elisa fez isso ao introduzir o termo tumor na aula de neoplasia e relembrou aos estudantes: "A gente já falou sobre este termo. Já o utilizou em outros assuntos. Não foi? Quando é que a gente falou de tumor? Na inflamação/ quando a gente estava falando / se referindo ao edema na região." Ao salientar isso, a professora retomou um conceito já estudado e demonstrou que ele passou a ter um significado diferente quando o tema é neoplasia. Ela explicitou que o termo tumor, na inflamação, significa aumento de volume devido ao inchaço, ao passo que, em neoplasias, ele é utilizado como sinônimo de crescimento celular anormal.

\section{c) Relações pedagógicas de continuidade do tipo macro}

As RPs macro, neste trabalho, serão subdivididas em RPs macro curriculares e RPs macro profissionais.

(c.1) Relações pedagógicas macro curriculares

$\mathrm{Na}$ relação pedagógica macro curricular, os docentes associam conceitos do conteúdo da Patologia Geral com aqueles de outras disciplinas do currículo.

(c.1.1) Relações pedagógicas macro curriculares implícitas: nessa RP, o professor não evidencia em qual disciplina aquele conceito foi ou será estudado.

Um exemplo desse tipo de RP ocorreu quando Ana, em uma aula de neoplasia, explicava o conceito de diferenciação celular. Ela iniciou a explanação dizendo que todos as células do corpo surgiram de uma única e que essa, multiplicou-se e diferenciou-se nas demais. Em um determinado momento da aula, comentou quais eram as células mais diferenciadas e perguntou por qual motivo, essas células, não podiam fazer mitose. Respondeu, relembrando: "Para sofrer mitose/ o que a célula precisa fazer/ durante o processo de mitose. Ela precisa/ aumentar o componente celular/ as organelas. Parar a função para poder aumentar a quantidade de DNA/ para dividir para as duas células filhas. Neurônio pode parar função/ para organizar/ / aumentar a quantidade de organelas e material genético? Não. Então/ ele é uma célula tão especializada que não pode entrar nesse processo de mitose."

Ao fazer isso, ela retomou conceitos já estudados em outras disciplinas, como Citologia e Histologia Geral e Genética, porém em sua explicação não deixou claro em qual disciplina eles haviam estudado o tema.

(c.1.2) Relações pedagógicas macro curriculares explícitas: nela, o professor destaca em qual disciplina aquele conceito foi ou será aprendido.

Um exemplo ocorreu durante a explicação de Carlos a um estudante, acerca da função do sistema imune e de sua ação frente às células tumorais. Ele disse: "Vocês tiveram isso em imunologia! Não tiveram? Imunologia dos tumores?’. Já Paulo, efetuou uma RP desse tipo ao explicar a carcinogênese viral quando perguntou aos estudantes: "O que / que é uma célula permissiva? Lá na microbiologial quando falava de vírus??"

Percebe-se, por meio desses fragmentos, que os professores retomam conceitos vistos pelos estudantes ao longo do curso, para construir outro conceito na Patologia. 
(c.2) Relações pedagógicas macro profissionais

Nesse tipo de RP, o professor associa o conteúdo da Patologia Geral ao exercício da profissão, evidenciando assim a importância da Patologia Geral para a futura profissão. De certa forma, isso engaja o estudante à disciplina, pois mostra que determinado conteúdo da patologia é utilizado em termos profissionais.

(c.2.1) Relações pedagógicas macro profissionais explícitas

Tom, ao explicar a importância das características hereditárias no surgimento dos cânceres, disse: "É nessa hora/ que você como veterinário/ vai perguntar para o dono do animal // O cachorro chega com suspeita de câncer/ antes de fazer qualquer coisa/ de examinar/ você vai perguntar: Do que o pai dele morreu? Do que a mãe do cachorro morreu? Porque no câncer a hereditariedade tem um papel." Ao fazer isso ele situou, dentro da futura profissão do estudante, aquilo que estava sendo explicado - o papel genético na formação das neoplasias. Como essa RP está evidentemente relacionada à profissão, ela foi classificada como macro profissional explícita.

(c.2.2) Relações pedagógicas macro profissionais implícitas

Ana utilizou a modalidade RP macro profissional implícita, ao explicar a displasia para os estudantes de Medicina. Ela iniciou o fragmento retomando as características normais de um útero e então relatou: "Então/ você faz um exame que chama Papanicolau/ faz um esfregaço dessas células e as vê assim: núcleo/ citoplasma/ então está normal! Vocêl tanto faz um esfregaço com swab daqui da ectocervix/ quanto daqui da endocervix. Então/ você faz um swab de novo/ após um tempo. Forma está ligada à função. Você vê isso aqui (indica na tela projetada). Então está esquisito/ não está? Em relação à primeira/ que está normal. As células estão com tamanho/ cor e núcleo alterados. Então/ tem um maior número de células aqui (indica na tela projetada). Essas células mudaram/ / além de aumentarem em número/ alteraram seu fenótipo. Isso aqui é uma displasia ligeira." Ela continuou o fragmento, comentando a evolução das displasias. Ao fazer isso, ela ligou a Patologia Geral implicitamente a uma das especialidades médicas - a Ginecologia - utilizando uma lesão básica que remete à evolução de uma doença muito comum e importante na prática médica que é o câncer de colo de útero.

\section{Quantificação das RPs}

A seguir apresentaremos as frequências com que as RP's apareceram na sequência de neoplasia de cada professor.

Verificamos que a RP de continuidade meso foi a mais frequente das RPs estudadas (183) e foi a mais efetivada pelos professores Paulo, Ana e Elisa (Figura 3). Além disso, a RP meso tem uma distribuição bastante homogênea entre os professores, o que não acontece para as outras relações pedagógicas.

A segunda abordagem mais comum entre os professores foi a micro (179), na qual o professor Carlos, destacou-se na quantidade de RPs feitas.

Ao analisarmos a RP macro, verificamos que as relações com o currículo (95) são mais comuns do que com a profissão (50). Quando subdividimos a relação com o currículo, as relações implícitas (68) são mais usuais do que as explícitas (27) (Figura 3). Na modalidade macro profissionais os valores das RP's explícitas (27) e implícitas (23) foram próximos (Figura 3). Já nos exemplos contextualizados, a frequência foi de 70 aparições. Observamos também, que as RPs macro foram menos expressivas (145 somando os diferentes tipos) nas aulas dessa disciplina, quando comparadas com as RPs micro (179) e meso (183). 
Figura 3. Número total de relações pedagógicas encontradas em 17 aulas com o tema neoplasia, de cinco professores da disciplina de Patologia Geral

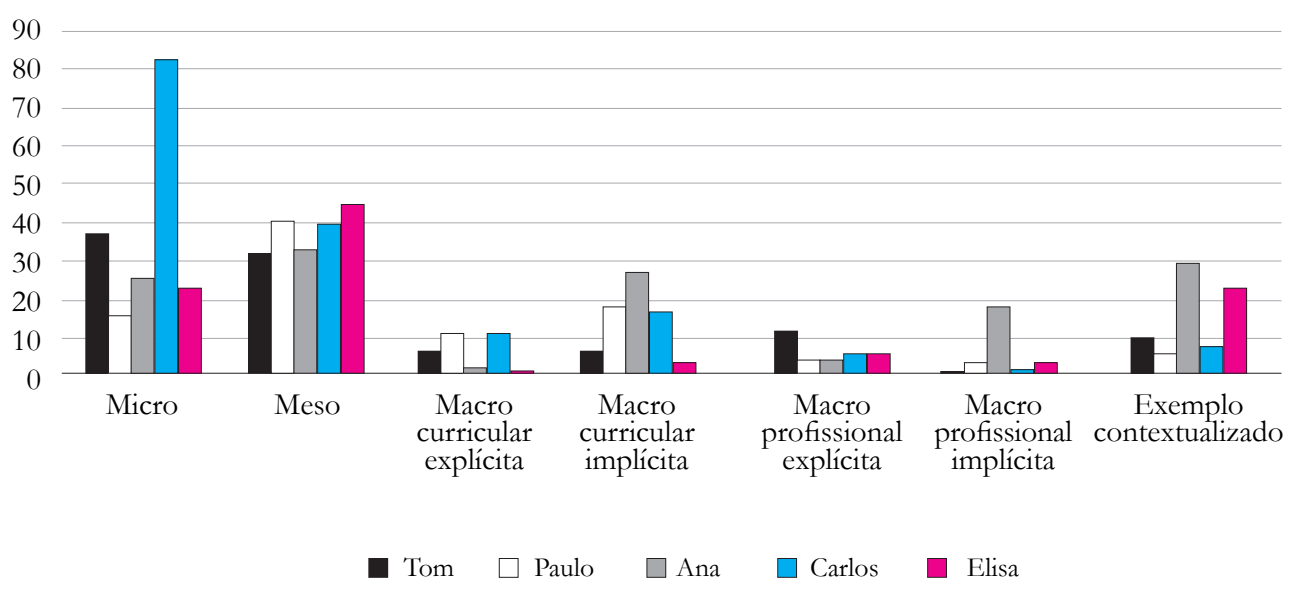

Fonte: elaborada pelos autores.

\section{Os Professores}

O professor, para exercer a docência, traz os saberes da vivência profissional que foram construídos por ele em seu dia-a-dia, permeado pelo processo de reflexão crítica sobre a prática em sala de aula, enriquecida pelas contribuições das experiências pedagógicas dos seus pares de profissão, bem como pelo suporte da pesquisa e pelo investimento em estudos correlatos à sua área de atuação (PEREIRA; BEHRENS, 2010). Isso faz com que cada professor tenha um desempenho único em sala de aula. Assim, o uso das RPs é idiossincrático e, dessa forma, cada um dos professores se destaca ao usar um ou mais tipos de RPs.

Portanto, traremos alguns trechos de uma entrevista semiestruturada para apresentaremos o possível motivo pelo qual alguns professores destacaram-se em uma ou mais categorias de RP.

Ana é bióloga e ministrava aulas para a turma de Medicina. Embora a professora não tenha a experiência de campo, ela tenta sempre trazer exemplos com base em pesquisas que faz na literatura, para garantir que os processos patológicos básicos deem suporte para o entendimento das doenças. Durante sua entrevista, ela enfatizou o papel do professor como mediador na aprendizagem dos estudantes. Isso pode ser observado quando a professora Ana foi perguntada sobre qual seria seu entendimento sobre o processo de ensino e aprendizagem e respondeu: "Temos que gerar uma base para que o aluno consiga formar o seu conceito sobre alguma coisal um tema que a gente esteja discutindo. [...] O professor exerce importante papel na formação dos estudantes." Quando indagada sobre qual a importância de ser professor no ensino superior, ela retomou a mesma ideia que o professor tem um papel central na formação do estudante.

Carlos é Médico Veterinário e era docente de uma turma de Farmácia e parece ter grande interesse no aprendizado dos estudantes. Isso pode ser observado quando relatou, 
ao ser entrevistado, sobre sua preocupação com a aprendizagem dos estudantes. O professor Carlos contou-nos que, quando trabalhava em outra instituição de ensino superior, deparou-se com uma turma na qual havia vários estudantes com problemas de aprendizagem e decidiu, juntamente com outros docentes, mudar aquela situação. Segundo ele, após essa experiência, sua forma de ministrar aulas transformou-se: “[...] e/ mudou completamente / meu estilo de ensino e (3s) e de ministrar a aula mudou completamente." Outro indício apareceu quando ele foi perguntado sobre o que entendia por ensino e aprendizagem e narrou o seguinte: "Eu sinceramente quando dou aula espero muito / que aquilo que eu esteja falando / fique claro para os meus alunos. Então / o processo de ensino daquilo que eu tento passar/ tento passar da forma mais didática e melhor possivel para que eles entendam."

Desse grupo de professores, Elisa é a que possui menor experiência docente, mas mesmo assim, notamos que ela se esforçou em conectar a disciplina e se empenhou na aquisição de conhecimentos por seus estudantes, que pode ser reflexo de sua experiência pessoal. Quando era estudante, ela relatou que a estratégia de ensino usada por sua professora não foi a mais adequada, conforme relatado: "Eu gostava da matéria. [...] O método/ [...] a gente passava a aula inteira sublinhando o livro e a professora ficava sentada e a gente tinha um livro pequenininho (faz gesto indicando um livro grosso) / assim. E ela lia e mandava a gente sublinhar. [...]." Além do mais, quando perguntamos se ela se inspirava em algum professor para ministrar suas aulas, ela relatou que se inspirou nas boas práticas e se salvaguardou de não realizar as ruins. Também nos apoiamos em sua narrativa de qual é o significado de ser professor universitário: "Pessoalmente uma realização (2s) para mim/ assim/ profissional. É o que eu sempre quis (2s) fazer e depois que eu conseguil que en comecei / en tive a certeza de que é o que en gosto. E eu acho que é uma responsabilidade muito grande. A gente tem/ esse papel/ de lidar com as pessoas e não educar/ mas transmitir um conhecimento e aprender muito também com essas pessoas com quem a gente tem convívio." Elisa é formada em Odontologia e lecionava para este mesmo curso.

Paulo é Médico Veterinário e era docente de Biomedicina. Foi um dos professores filmados, que mais interagiu com os estudantes. O que pode ser resultado de sua experiência quando estudante de patologia: "A aula era baseada simplesmente numa demonstração de slides sem interatividade com o aluno." Um outro fator que nos chamou a atenção foi sobre a dificuldade para entender a Patologia Geral quando era estudante de Medicina Veterinária. Na entrevista, perguntado sobre sua percepção do ensino de patologia, quando estudante, sua narrativa foi a seguinte: "Era uma disciplina difícil. Eu não entendia nada. Na patologia geral eu simplesmente / eu não entendia porque eu estava fazendo Patologia. Não entendia a temática. A maioria dos conceitos passavam despercebidos/ eu não conseguia compreender."

Tom possui uma ampla experiência prática profissional. Tom é formado em Medicina Veterinária e atua como Patologista, realizando necropsias e analisando lâminas para dar diagnóstico histopatológico. Isso permite um acúmulo de experiência que ele pode compartilhar com os estudantes de Medicina Veterinária em sala de aula, por meio de exemplos concretos. Porém, na entrevista quando perguntamos a Tom: "Qual era a sua percepção do ensino de patologia, quando você era estudante?", ele deixou claro como foi negativa sua experiência como estudante de Patologia Geral quando cursou Medicina Veterinária: “Ah eu tinha muitos problemas com a patologia particularmente a patologia daqui [...] Não tinha nenhum veterinário no departamento de Patologia Geral/ o curso era dado por médicos/ era uma Patologia Médica / completamente voltada para a Medicina e os exemplos eram todos eles de Medicina e muitas e muitas vezes a gente se perguntava que diabos isso tem a ver com Veterinária [...] então en ficava com a pergunta por que então / está sendo apresentado para um curso veterinária?" 


\section{Discussão}

Os docentes investigados seguem o padrão já retratado na literatura para professores do ensino superior (PIMENTA; ANASTASIOU, 2010; SÁ et al., 2018), ou seja, possuem um grande conhecimento específico e pouco conhecimento pedagógico. Isso pode ser notado na transcrição das falas de alguns professores, como por exemplo: "educar é dar a base"; "ser didático é apresentar os conteúdos com clareza"; "a gente tem o papel de lidar com as pessoas e não educar, mas transmitir conhecimento". Com isso, o que se nota é que a visão que eles têm sobre educação limita-se a certas afirmações de senso comum, que expressam a falta de formação pedagógica desses professores. Desse modo, concordamos com Ribeiro (2012), ao dizer que a construção da prática desses docentes é apoiada nos moldes aprendidos com seus professores no tempo em que eram estudantes. Nesse sentido, eles exercem a ação pedagógica da forma que consideram correta. Julgamos também, que o contraexemplo alicerçou a prática docente de nossos investigados (QUADROS, 2010), uma vez que a maioria deles relatou ter tido uma vivência difícil com a disciplina.

Apesar disso, notamos que eles efetuam as RPs investigadas, apresentando maior frequência das RPs micro e meso. Esse achado comungou com o encontrado por Quadros, Silva e Mortimer (2018) em um estudo envolvendo professores de várias áreas do conhecimento. Uma explicação para isso é que, sendo especialista em sua área de saber, o professor faz essas RPs com facilidade, mesmo que ele as desconheça.

Ao trabalhar as RPs micro e meso, os estudantes aprendem de forma cumulativa e contínua. Assim, constroem evolutivamente os significados, estabelecendo no contexto presente uma conexão com contextos anteriores (BADREDDINE, 2012).

Entretanto, quando partimos para a ligação dos conceitos da disciplina com o currículo ou com a profissão (RPs macro profissional, macro curricular e exemplos contextualizado), a frequência é bem menor. Isso, como mostrado por Silva et al. (2015), pode ser um reflexo da tradição do professor universitário de cuidar de sua especialidade e de nem sempre entender e conhecer sua responsabilidade de relacionar-se com as demais áreas do conhecimento.

No caso da Patologia Geral, as RPs macro e exemplos contextualizados deveriam sempre vir à tona, considerando a complexidade e a importância da disciplina para os estudantes da área de saúde. Isso porque, como toda disciplina do ensino profissional, ela é ensinada em módulos e pode ocorrer que o estudante não faça a relação dela, com o mundo concreto. Correndo o risco então, de transformar o conhecimento do estudante num conjunto de explicações e generalizações sem fundamento prático (QUADROS; SILVA; MORTIMER, 2018). Dessa forma, como o valor da disciplina não está sendo explicitado, os estudantes podem demandar maior interação entre a disciplina e a futura profissão, como foi observado nos resultados de um questionário utilizado em uma pesquisa paralela, já mencionado anteriormente.

Acreditamos que o uso frequente das RPs macro explícitas e de exemplos contextualizados, além de descompartimentalizar o programa do curso, pode fazer o que é essencial para a Patologia Geral, que é a materialização do elo que ela representa entre as disciplinas básicas e as profissionalizantes. 


\section{Conclusões}

O conhecimento e a utilização das RPs desenvolvidas por Scott, Mortimer e Ametller (2011) são importantes, pois sua efetivação pelo professor propicia a organização e continuidade dos temas nas suas aulas, ao gerar coesão ao discurso. As RPs também potencializam a descompartimentação do conteúdo da disciplina e promovem melhor entendimento do currículo, pelos estudantes. Além disso, elas sinalizam a importância daquela disciplina para a profissão futura. Isso tudo pode fomentar o engajamento com a disciplina e facilitar a aprendizagem. Fazendo as relações pedagógicas na Patologia Geral, o professor pode promover um dos objetivos da disciplina, que é ser um elo entre as disciplinas básicas e as profissionalizantes.

Além disso, ao fazer essas relações pedagógicas, esses professores possibilitam aos estudantes uma visão mais ampla do currículo, já que os alunos percebem que um conteúdo trabalhado em outra disciplina tem ligação com o conteúdo que está sendo estudado naquele momento ou que este dialoga com o conteúdo futuro ou até mesmo com a atuação profissional.

Observamos que a utilização dessas relações pedagógicas em sala de aula está ligada ao desempenho de cada professor, que por sua vez, é influenciado pela história acadêmica e profissional de cada um.

Entretanto, quando se compara as RPs macro e os exemplos contextualizados com as RPs micro e meso, observamos que as primeiras ocorrem em menor frequência. Isso pode justificar, pelo menos parcialmente, o desinteresse dos estudantes nas aulas de Patologia geral, uma vez que o elo não está sendo efetivamente realizado.

O conhecimento da existência dessas relações pedagógicas pelos professores pode melhorar seu desempenho em sala de aula, pois isso permite que eles planejem suas aulas considerando fazer essas relações conscientemente. Dessa forma, elas poderão ser usadas de maneira adequada de modo a propiciar experiências produtivas para os seus estudantes. Para tanto, é extremamente importante também que o professor conheça o currículo daquele curso, assim como as características daquele profissional que está sendo formado.

Por fim, considerando a importância que as relações pedagógicas têm no desenvolvimento da estória científica, no conhecimento do currículo, na aproximação do curso com a vida profissional e na efetivação do elo que a Patologia Geral representa nos currículos da área da saúde, sugerimos então, que esse assunto possa ser debatido em cursos de desenvolvimento profissional de professores que são oferecidos na universidade em que lecionam.

\section{Referências}

BADREDDINE, Z. Building context and continuity in classroom discourse; a case study at the high school level. In: BRUGUIÈRE, C.; TIBERGHIEN, A.; CLÉMENT, P. (Ed.). E-book proceedings of the ESERA 2011 conference: science learning and citizenship. Lyon: European Science Education Research Association, 2012. Part 6, p. 1-7. Disponível em: <www.dropbox.com/s/9cckaddfooh24sg/ebook-esera2011.pdf?dl=0>. Acesso em: 4 mar. 2015. 
BRASIL. Lei $\mathbf{n}^{\circ}$ 9.394, de 20 de dezembro de 1996. Estabelece as diretrizes e bases da educação nacional. Brasília, 1996. Disponível em: < http://www.planalto.gov.br/ccivil_03/ leis/19394.htm>. Acesso em: 3 out. 2018.

BRASILEIRO FILHO, G. Bogliolo: patologia geral. 5. ed. Rio de Janeiro: Guanabara Koogan, 2013.

FENDERSON, B. A. Strategies for teaching pathology to graduate students and allied health professionals. Human Pathology, Dordrecht, v. 36, n. 2, p. 146-153, 2005. Disponível em: <https:/ /doi.org/10.1016/j.humpath.2004.09.022>. Acesso em: 3 out. 2018.

KUMAR, V. et al. Patologia: bases patológicas das doenças. 8. ed. Rio de Janeiro: Elsevier, 2010.

LEACH, J.; SCOTT, P. Designing and evaluating science teaching sequences: an approach drawing upon the concept of learning demand and a social constructivist perspective on learning. Studies in Science Education, Leeds, v. 38, n. 1. p. 115-142, 2002. Disponível em: <https://doi.org/10.1080/03057260208560189>. Acesso em: 3 out. 2018.

MARSHALL, R.; CARTWRIGHT, N.; MATTICK, K. Teaching and learning pathology: a critical review of the English literature. Medical Education, Plymouth, v. 38, n. 3, p. 302-313, 2004. Disponível em: <https://doi.org/10.1111/j.1365-2923.2004.01775.x>. Acesso em: 3 out. 2018.

MELO-JÚNIOR, M. R. et al. Integrando o ensino da patologia às novas competências educacionais. Ciências \& Cognição, Rio de Janeiro, v. 12, p. 110-114, 2007. Disponível em: <http://www.cienciasecognicao.org/pdf/v12/m347177.pdf>. Acesso em: 2 out. 2018.

MORTIMER, E. F. et al. Uma metodologia para caracterizar os gêneros de discurso como tipos de estratégias enunciativas nas aulas de ciências. In: NARDI, R. A pesquisa em ensino de ciência no Brasil: alguns recortes. São Paulo: Escrituras, 2007. p. 53-94.

NEVES, F. B. C. S et al. Impacto da introdução de mídia eletrônica num curso de patologia geral. Revista Brasileira de Educação Médica, Brasília, v. 32, n. 4, p. 431-436, 2008. Disponível em: <https://doi.org/10.1590/S0100-55022008000400004>. Acesso em: 2 out. 2018.

PEREIRA, L.; BEHRENS, M. A. Desenvolvimento docente no ensino superior: visibilidade e atuação profissional. Práxis Educativa, Ponta Grossa, v. 5, n. 1. p. 39-46, Jan./Jun. 2010. Disponível em: <https://doi.org/10.5212/PraxEduc.v.5i1.039046>. Acesso em: 2 fev. 2016.

PIMENTA, S. G.; ANASTASIOU, L. Docência no ensino superior. 4. ed. São Paulo: Cortez, 2010.

QUADROS, A. L. Aulas no ensino superior: uma visão sobre professores de disciplinas científicas na licenciatura em química da UFMG. 2010. 293 f. Tese (Doutorado em Educação) - Faculdade de Educação, Universidade Federal de Minas Gerais, Belo Horizonte, 2010 . 
O uso de Relações Pedagógicas em aulas de Patologia Geral: ...

QUADROS, A. L.; SILVA, A. S. F.; MORTIMER, E. F. Relações pedagógicas em aulas de ciências da educação superior. Química Nova, São Paulo, v. 41, n. 2, p. 227-235, 2018. Disponível em: <https://doi.org/10.21577/0100-4042.20170178>. Acesso em: 2 out. 2018.

REISNER, H. M. Patologia: uma abordagem por estudos de casos. Porto Alegre: AMGH, 2016.

RIBEIRO, M. C. R. A construção da aula no ensino superior: concepções de professores iniciantes da universidade estadual do Piauí. In: CONGRESO INTERNACIONAL SOBRE PROFESORADO PRINCIPIANTE E INSERCIÓN PROFESIONAL A LA DOCENCIA, 3., 2012, Santiago de Chile. Actas... Disponível em: < http://congressoprinc. com.br/artigo?id_artigo=298>. Acesso em: 2 out. 2018.

SÁ, E. F. et al. Caracterização de aulas de graduação na perspectiva dos professores. In: MORTIMER, E. F.; QUADROS, A. L. (Org.). Multimodalidade no ensino superior. Ijuí: Unijuí, 2018.

SANTOS, F. M. T. Do ensino de ciências como mudança conceitual à fronteira de uma abordagem afetiva. 1996, 171 f. Dissertação (Mestrado em Educação) - Cento de Ciências da Educação, Universidade Federal de Santa Catarina, Florianópolis, 1996.

SCOT'T, P.; MORTIMER E.; AMET'TLER J. Pedagogical link-making: a fundamental aspect of teaching and learning scientific conceptual knowledge. Studies in Science Education, London, v. 47, n. 1. p. 3-36, 2011. Disponível em: <https://doi.org/10.1080/03057267.2011. 549619>. Acesso em: 2 out. 2018.

SILVA, A. S. F. et al. As conexões do conteúdo no ensino superior: análise a partir de cinco professores. In: ENCONTRO NACIONAL DE PESQUISA EM EDUCAÇÃO EM CIÊNCIAS, 10., 2015, Águas de Lindóia. Anais... Disponível em: <http://www.abrapecnet. org.br/enpec/x-enpec/anais2015/lista_area_17.htm>. Acesso em: 2 out. 2018.

TAVARES, A. C. O ensino da patologia humana e suas relações históricas com o estilo de pensamento a partir da análise de livros-texto. 2008. 112 f. Dissertação (Mestrado em Educação) - Faculdade de Educação, Universidade de Brasília, Brasília, 2008.

VASCONCELOS, A. C. Patologia geral em hipertexto. [2000]. Disponível em: < http:// depto.icb.ufmg.br/dpat/old/pathip.htm>. Acesso em: 13 mar. 2018.

Artigo recebido em 14/05/2018. Aceito em 01/08/2018.

Contato: UFMG, Avenida Presidente Antônio Carlos, 6627, Campus UFMG, Belo Horizonte, MG, 31270-901, Brasil. 
